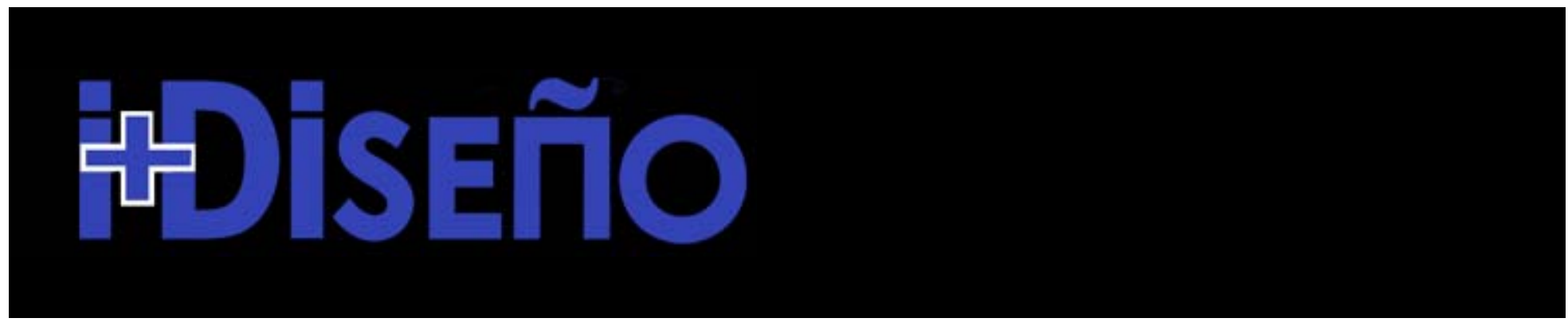

i+Diseño | Vol. 11 | Abril | Año VIII

\title{
Emilio Gil: Diseño en tres tiempos
}

\section{Resumen}

Emilio Gil fundó, junto a otros tres socios, Tau Diseño en 1980 a partir de un pequeño estudio anterior cuando se dieron las circunstancias que hacían necesario profesionalizar la estructura de algo que había venido funcionando sin una base empresarial hasta entonces.

Entre los cuatro socios fundadores no había ningún titulado en Diseño. Procedían del campo de la Arquitectura, el Periodismo o incluso un licenciado en Filosofía Pura. En los años en los que Tau Diseño se constituye, lo habitual era la práctica de la profesión a título individual: pequeños estudios alrededor de una persona que, en algunos casos, se valía de algún ayudante maquetador o arte finalista. Sin embargo Tau nació con la intención de ser un grupo de profesionales que se complementaran en sus diferentes especialidades.

El diseñador declara que su intención no era formar un estudio propio sino todo lo contrario: una aventura compartida que respondía a su concepción del diseño como adecuación a unos objetivos, al margen de un estilo personal, y no como obra de autor con una impronta de estilo personal.

Fiel a este planteamiento Emilio Gil presenta en este artículo tres proyectos que responden a esas intenciones: un libro de referencia sobre la historia reciente de nuestro Diseño: Pioneros del Diseño Gráfico en España, la imagen del Máster de Gestión Cultural de la Universidad Carlos III de Madrid y el cartel de la edición 75 de la Feria del Libro de Madrid.

Palabras clave: Tau Diseño, pioneros, gestión cultural, Feria del Libro, estilo de autor.

\section{Emilio Gil: three periods of Design}

\begin{abstract}
Before this research started, a major issue was faced: the lack of bibliography in Spanish language, either that written in Spanish or translated into Spanish from other language.

The above-mentioned issue had a demotivating effect on proceeding with the research work, nonetheless, in order to find solutions to the obstacles it faces and to find out the factors influencing the lack of such bibliography in Spanish, the research was finally carried out.

This study targets the Digital Matte Painting technique: how it works, a brief history of the technique, some authors and films that were elaborated using it.

The way in which this technique has helped in films will also be mentioned. Certain problems related to it will be presented, focusing on its status in Spain.

Throughout his research and scientific experience in the specific technique, the author has been able to identify the obstacles that mostly prevent its consolidation in all areas of its application at the national level (mainly in the film industry). The author therefore provides a set of suggestions that, in his opinion, would contribute in its reinforcement as a digital technique for countless artistic and creative possibilities.
\end{abstract}


He tenido la suerte de trabajar como diseñador gráfico a lo largo de más tres décadas. Tau Diseño, la empresa que junto a otros tres socios fundamos en 1980, ha recorrido una trayectoria que se asimila de forma bastante directa con la peripecia que el diseño español ha recorrido en este tiempo.

Tau Diseño se fundó a partir de un pequeño estudio anterior cuando se dieron las circunstancias que hacían necesario profesionalizar la estructura de algo que había venido funcionando sin una base empresarial. A veces me han preguntado por la razón del nombre Tau creyendo que responde a algún tipo de siglas. De hecho en la elección del nombre ya había una declaración de intenciones. Se eligió la letra griega tau intentando reflejar la vertiente humanística de la profesión y la conexión con el mundo de la cultura.

Entre los cuatro socios fundadores no había ningún titulado en Diseño. Procedíamos del campo de la Arquitectura, el Periodismo o incluso un licenciado en Filosofía Pura. En los años en los que Tau Diseño se constituye, lo habitual era la práctica de la profesión a título individual: pequeños estudios alrededor de una persona que, en algunos casos, se valía de algún ayudante maquetador o arte finalista. Sin embargo Tau nació con la intención de ser un grupo de profesionales que se complementaran en sus diferentes especialidades.

Los comienzos de Tau tuvieron todas las características del amateurismo si se considera desde el punto de vista empresarial. Al no tener formación como tal, el desarrollo y posterior crecimiento de Tau Diseño, dependía de intuiciones o decisiones más o menos acertadas o más o menos casuales. Se podría decir que la única forma de crecer era a base de aciertos en los resultados de cada proyecto y el efecto multiplicador que éstos podrían generar a partir de su difusión.
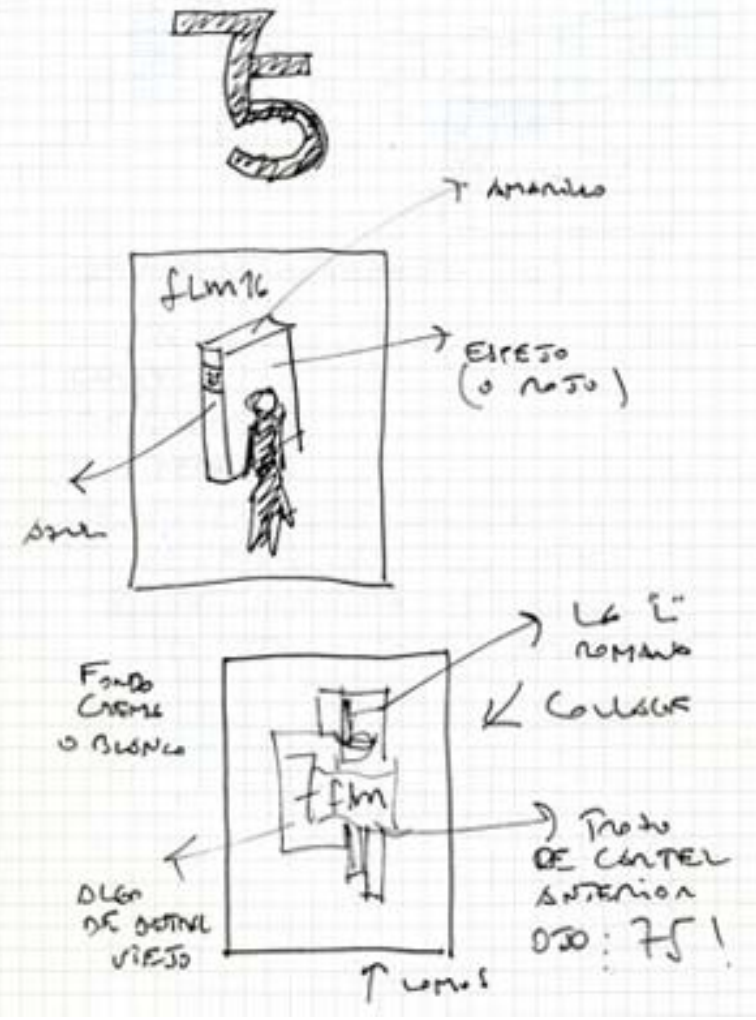

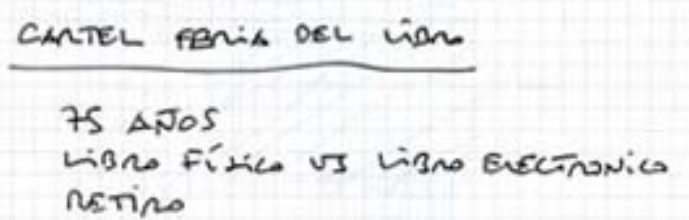

retirs

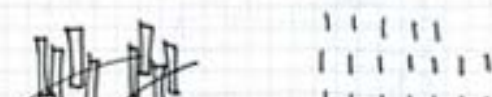

1111111

1111111

$11|1| 1 \mid$

1111111

$1|1| 1 \mid 1$

1111111

$11|1| 1 \mid$

I $1111|1|$

111111

75 Lotof of Liznol

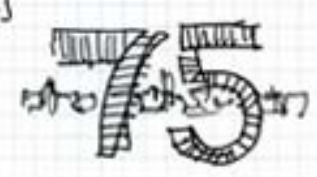

Fig. 1 y 2. Bocetos realizados por el estudio. 
En realidad yo no elegí un estudio propio sino todo lo contrario: una aventura compartida que respondía a mi concepción del diseño como adecuación a unos objetivos, al margen de un estilo personal, y no como obra de autor con una impronta de estilo personal.

Creo que soy un profesional que interviene en un proceso de transmisión de información buscando la solución formal adecuada.

Soy de lo que yo entiendo como la generación siguiente a los pioneros gráficos españoles aunque en cierta medida sí me considero un pionero que ha tenido la fortuna de trabajar en unos años muy especiales: cambios importantes en la sociedad española, descubrimiento por parte de la administraciones y el mundo empresarial de la necesidad del diseño, paso del mundo analógico al digital, aparición de los títulos universitarios en Diseño...

Vemos tres tiempos en estas tres décadas.

\section{Primer tiempo: Pioneros para la exportación}

En 2007 la editorial neoyorquina MBP publicó en el idioma inglés el libro Pioneers of Spanish Graphic Design que había sido editado unos meses antes por Index Book en su versión en castellano. La acogida del mercado y las recensiones aparecidas en los distintos medios especializados fueron un claro índice de que su contenido interesaba de forma notable al mundo del diseño internacional. Steven Heller en Eye Magazine, David Crowley del London Collage of Art, en Creative Review; las revistas Form, ArtLab o, el boletín de la St. Bride Library de Londres Ultrabold, así como los múltiples comentarios en blogs personales o colectivos fueron un claro exponente de que lo que se ha venido en llamar la generación de los pioneros del diseño gráfico español constituía una sorpresa inesperada y suscitaba una admiración y un reconocimiento absolutamente justificado para el talento de aquellos grafistas.

Con el libro Pioneros del Diseño Gráfico en España buscaba el objetivo de hacer conocer a las generaciones actuales de diseñadores la calidad del trabajo y la pertinencia de las propuestas de los pioneros, para entender cómo se puede ser moderno sin pretenderlo. Cómo es posible crear imágenes de una enorme potencia visual por encima de modas o tendencias y de las herramientas con las que se trabaja. Para los pioneros la solución no era el recurso de combinar — de forma consciente o inconscientemente- ingredientes que la moda impone en un momento determinado. Como afirma el historiador de arquitectura William Curtis hay una distancia sustancial entre los creadores que toman los tics específicos de un periodo y la gente que adquiere una profunda comprensión del tiempo al que pertenece. El mismo lenguaje puede derivar en una obra de arte o en un mero gesto de moda. 

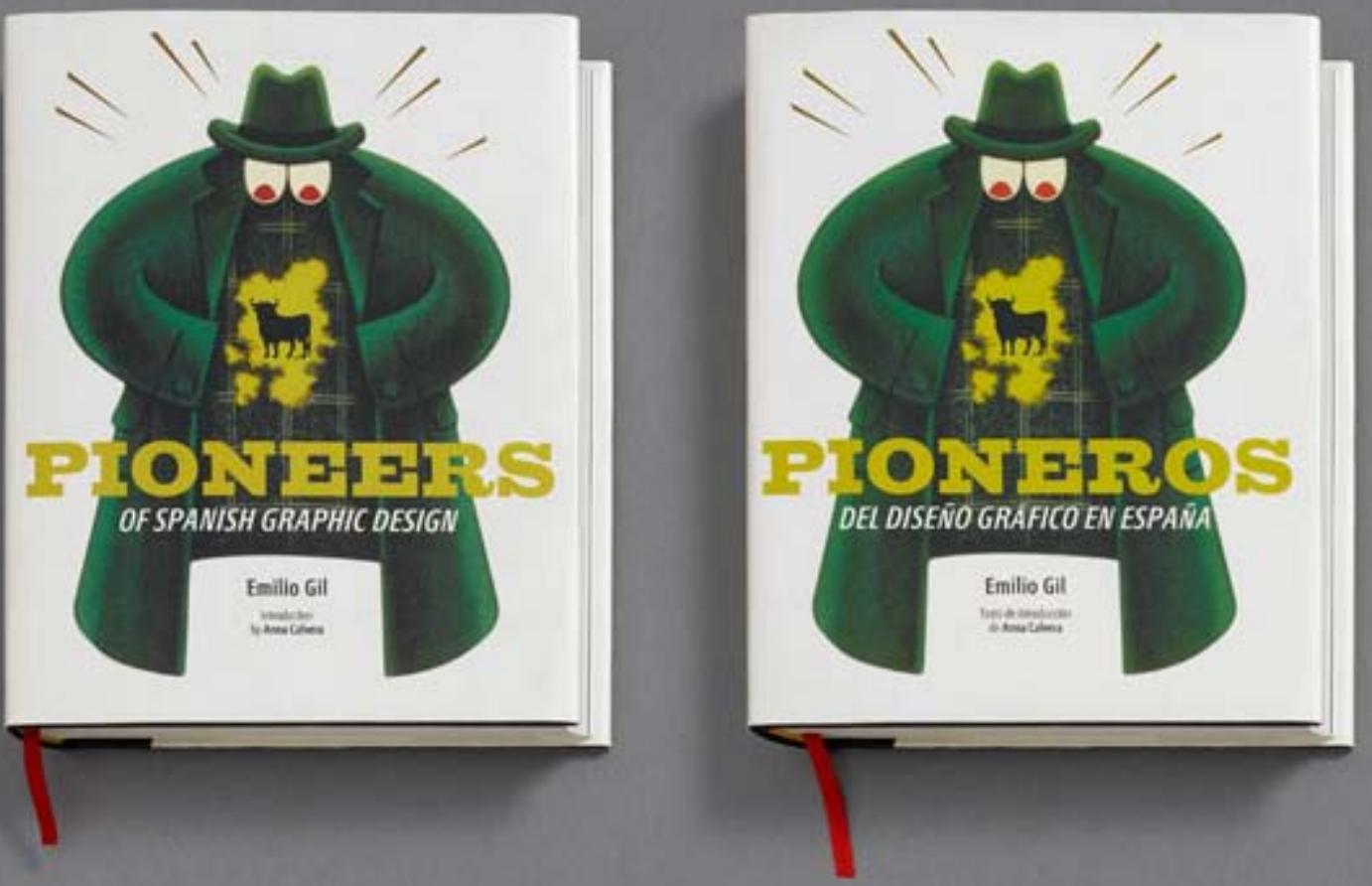

Fig. 3. Portada de Pioneros del Diseño Gráfico en sus distintas ediciones.

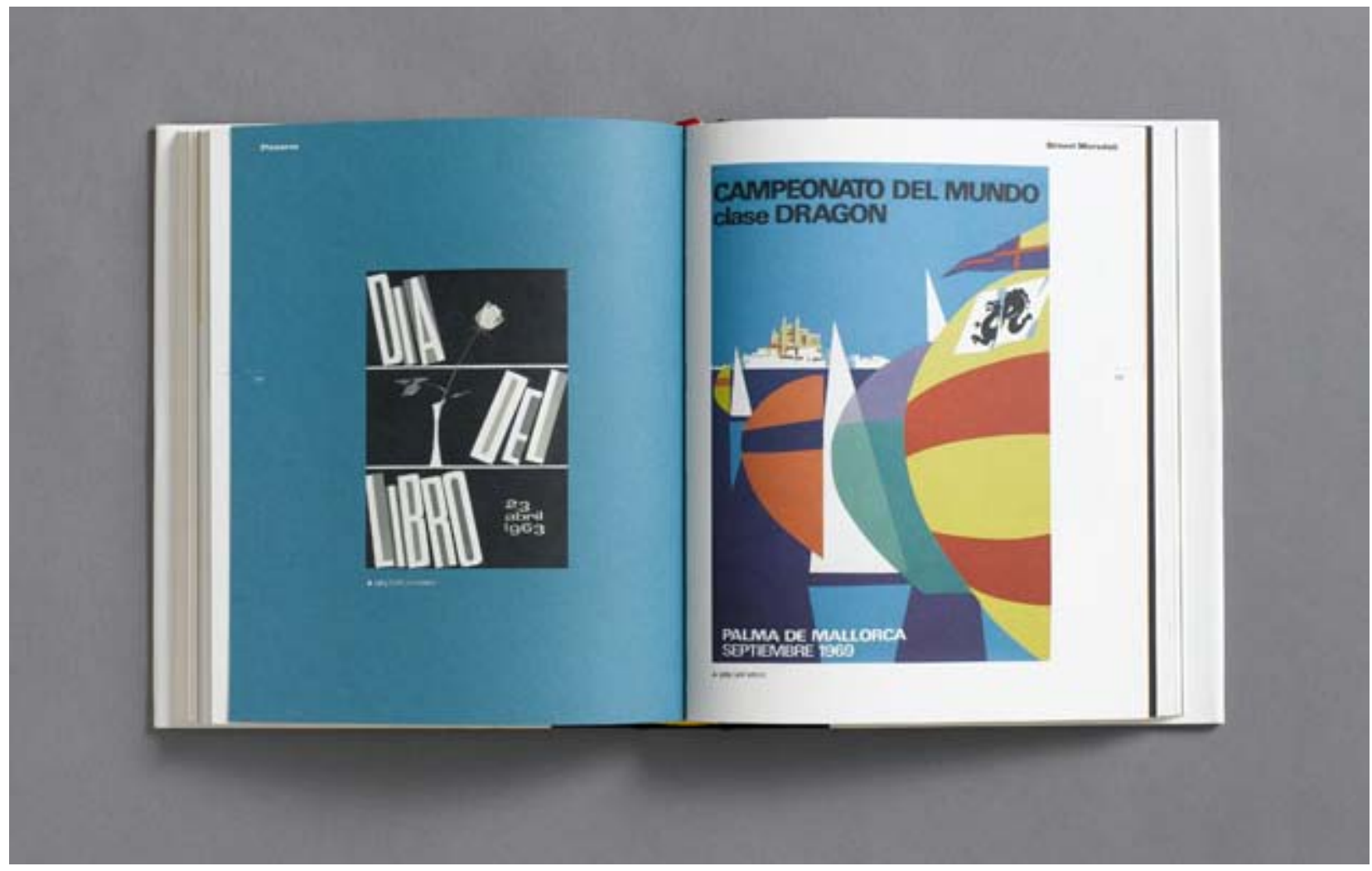

Fig. 4. Interior de Pioneros del Diseño Gráfico.

Para mi el trabajo de rastreo y recuperación de los pioneros españoles fue evidentemente un trabajo especial. Acostumbrado al día a día de la profesión como diseñador gráfico y al frente de una empresa de diseño con más de tres décadas de recorrido profesional, y a la labor de comisariado de exposiciones y profesor sobre temas relacionados con esta profesión, el poder enfrentarme con un trabajo de estas características, roza el ideal de mis intereses profesionales y, casi casi, 
personales: trabajo de búsqueda e investigación, establecer criterios de selección, rastreo de piezas, lecturas alrededor de una época brillante y significativa de la profesión, trato con mis maestros, encuentros y conversaciones... Días, semanas o meses de consulta en diferentes archivos. Cualquiera que conozca esta profesión por dentro se hará idea de que hay pocos proyectos que puedan aproximarse más a las ilusiones de un profesional del diseño.

\section{Segundo tiempo: la imagen del Máster de Gestión Cultural de la Universidad Carlos III}

"Ver es pensar con los ojos". La cita es de Ortega y Gasset el filósofo del raciovitalismo o, lo que es lo mismo, de la razón vital.

Intervengo en el Máster de Gestión Cultural de la Universidad Carlos III de Madrid desde hace una década, tratando de que futuros gestores culturales entiendan el Diseño Gráfico y Expositivo como una de las herramientas que manejarán en su día a día profesional. Y lo hago desde el convencimiento más profundo de que el Diseño también —no únicamente, pero tambiéncontribuye a la transmisión de conocimiento y tiende puentes entre los diferentes aspectos de la cultura y sus receptores.

La Universidad Carlos III cuenta con una Identidad Visual definida, clara y utilizada de forma rigurosa en toda su comunicación gráfica desde sus orígenes. Por ello plantearse una imagen particular para uno de sus másteres no dejaba de ser una aventura desde el punto de vista de la gestión de su marca gráfica y, por otra parte, un reconocimiento de la importancia que este máster había ido alcanzando hasta convertirse en el de referencia, entre los de su especialidad en España, y con un gran reconocimiento internacional.

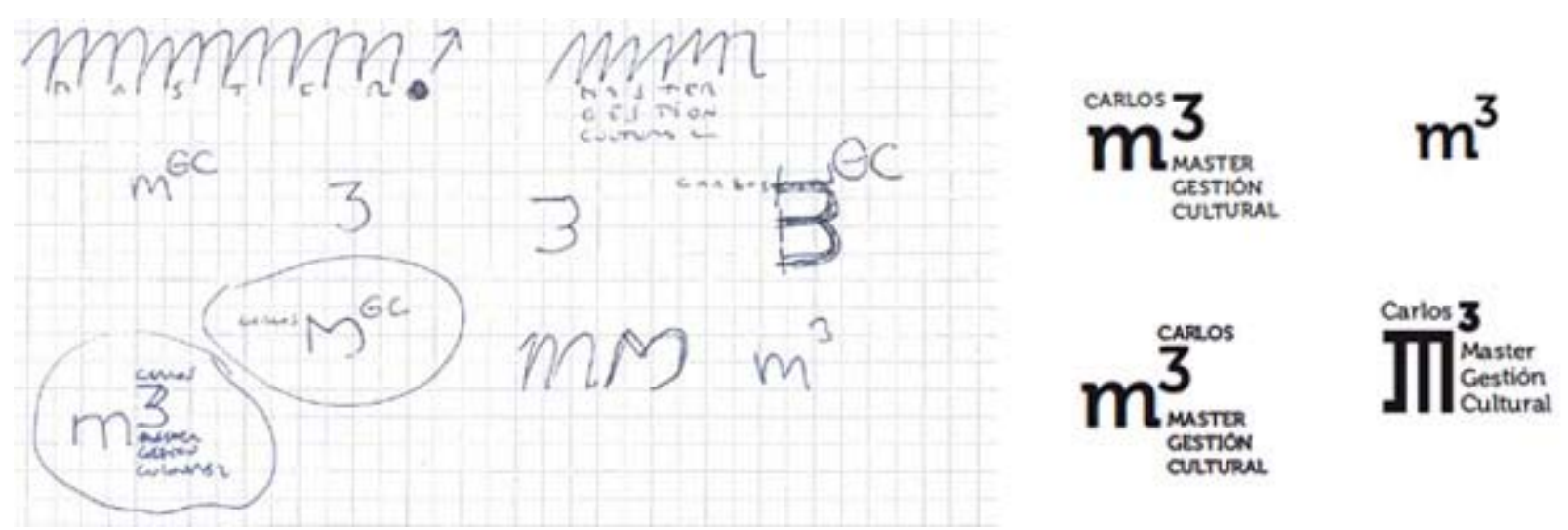

Fig. 5 y 6. Bocetos para logomarca del Máster Gestión Cultural.

En el arranque de mi trabajo pesaba la consideración de los contenidos tan variados que se tratan en el máster: artes plásticas, museos, exposiciones, galerías, edición, teatro, música, danza, cine o el mundo digital; contemplando además, desde el marco jurídico hasta la comunicación de proyectos o el amplio sector de las industrias creativas. ¿Cómo sintetizar en una imagen aspectos y campos tan diversos?

Cuando planteo el diseño de una logomarca me gusta pensar, desde el primer momento, en la línea gráfica posterior que se puede desarrollar a partir de ese símbolo básico. Todavía más en 
este caso en que la posibilidad de plantear un sistema que sirviera para asociarse a cada uno de los contenidos de la gestión cultural era no solo pertinente, sino absolutamente necesario.

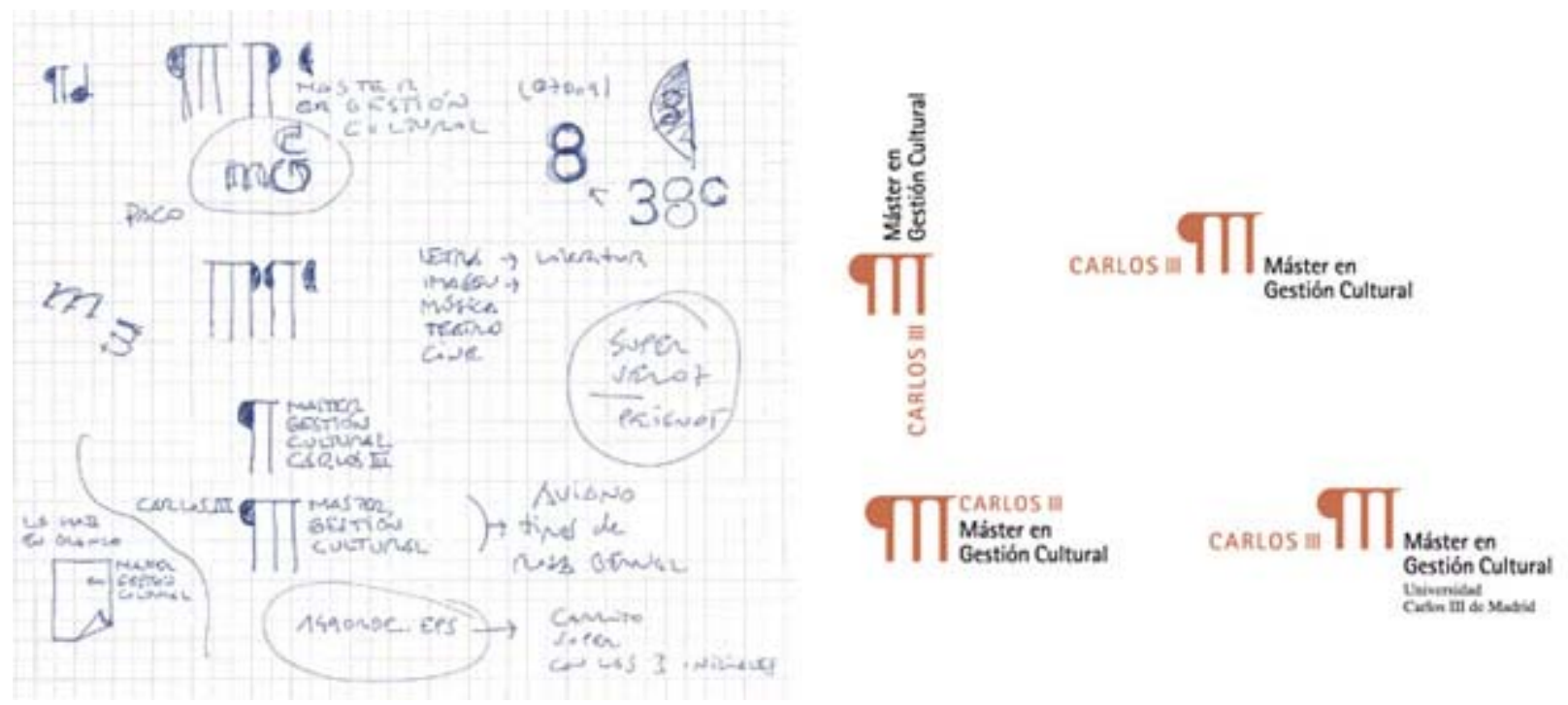

Fig. 7 y 8. Bocetos para logomarca del Máster Gestión Cultural.

"Ver es pensar con los ojos". Aquí es donde cobra sentido la cita con la que comenzaba. La gestión cultural se relaciona con aspectos que tienen una componente visual o formal en todos los casos. Incluso la expresión literaria, la palabra escrita, tiene su correlato gráfico o tipográfico. La gestión cultural nace de una reflexión, de la definición de una estrategia y la concreción de un programa, pero se expresa y se entiende con imágenes visuales.

En los primeros tanteos -esa borrachera de posibles caminos creativos que se produce en el inicio - planteé ideas a partir del número 3, incluido como ordinal, en el nombre de la institución educativa que acoge este máster: Carlos III o carlos3 como aparece en su dirección web.

Una vez desarrollados una serie de ensayos con el número 3, como recurso principal -el 3 y la potencia de 3 , o potencia al cubo como metáfora de las posibilidades de la cultura-, continué buscando otras líneas creativas y la solución llegó de la mano de uno de los signos tipográficos: el calderón o pilcrow en el idioma inglés.

Como muchos otros signos de puntuación, la marca asociada al término párrafo tiene una historia curiosa. La intención es ser reconocido como una "P" inicial de la palabra "párrafo" aunque esta circunstancia es irrelevante. En su forma original, esta marca era una " $\mathrm{C}$ " abierta, cruzada por una o dos líneas verticales: una abreviatura que los escribanos hacían para la palabra capitulum, la forma latina de nuestro término "capítulo".

Mi objetivo al elegir este signo tipográfico manipulándolo y convirtiéndole en un signo "ampliado" o con 3 "patas" era, por un lado, relacionarlo con la escritura, el pensamiento puesto en página, la tipografía como una de las herramientas principales del diseño gráfico y la tradición considerada en sentido amplio. Por otra parte, al ampliarlo, el signo cobraba una dimensión arquitectónica o espacial, matiz interesante al poder relacionarse, mediante este simple recurso, con otros aspectos del ámbito cultural. 

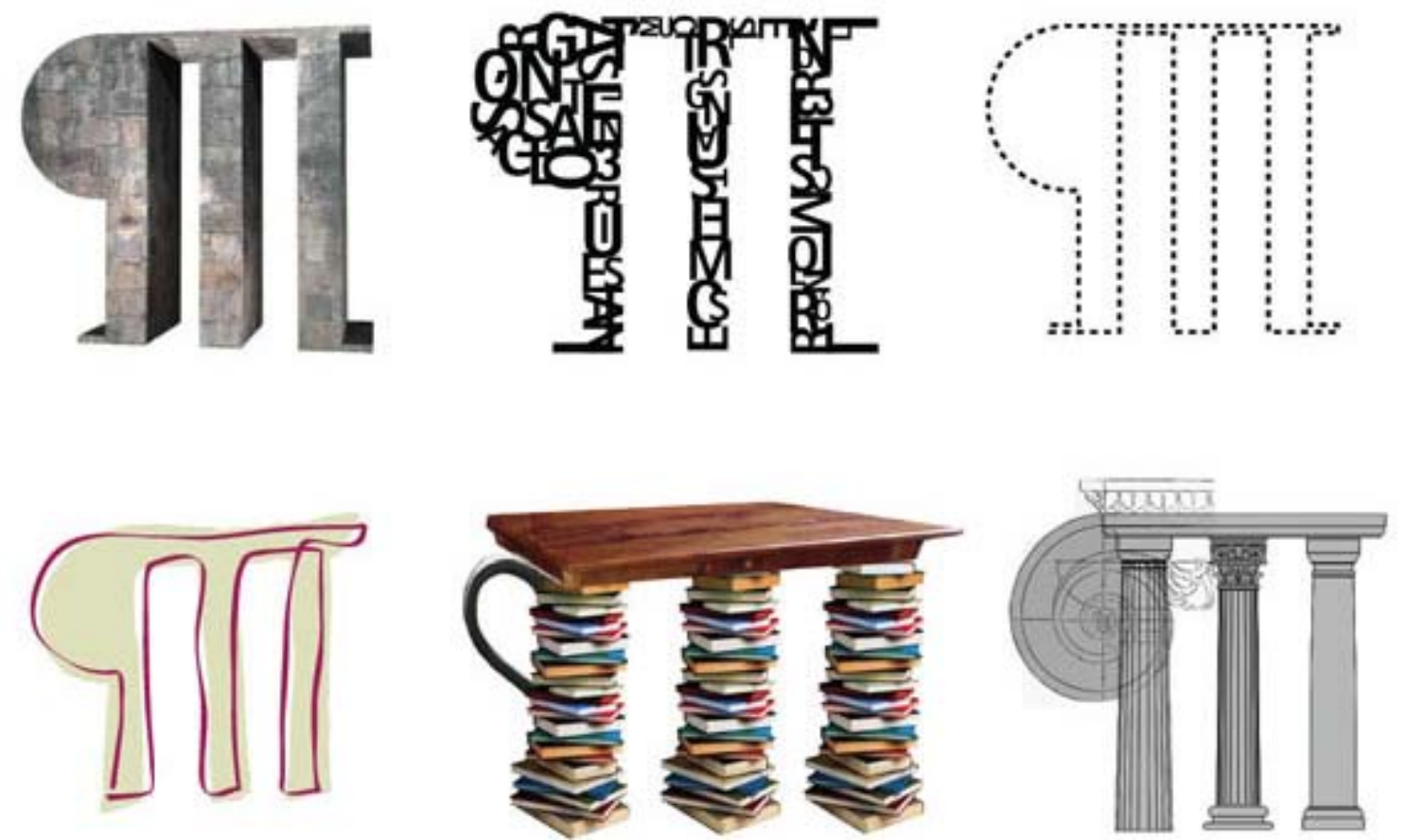

Fig. 9. Versiones e interpretaciones creativas del signo tipográfico usado en la logomarca.
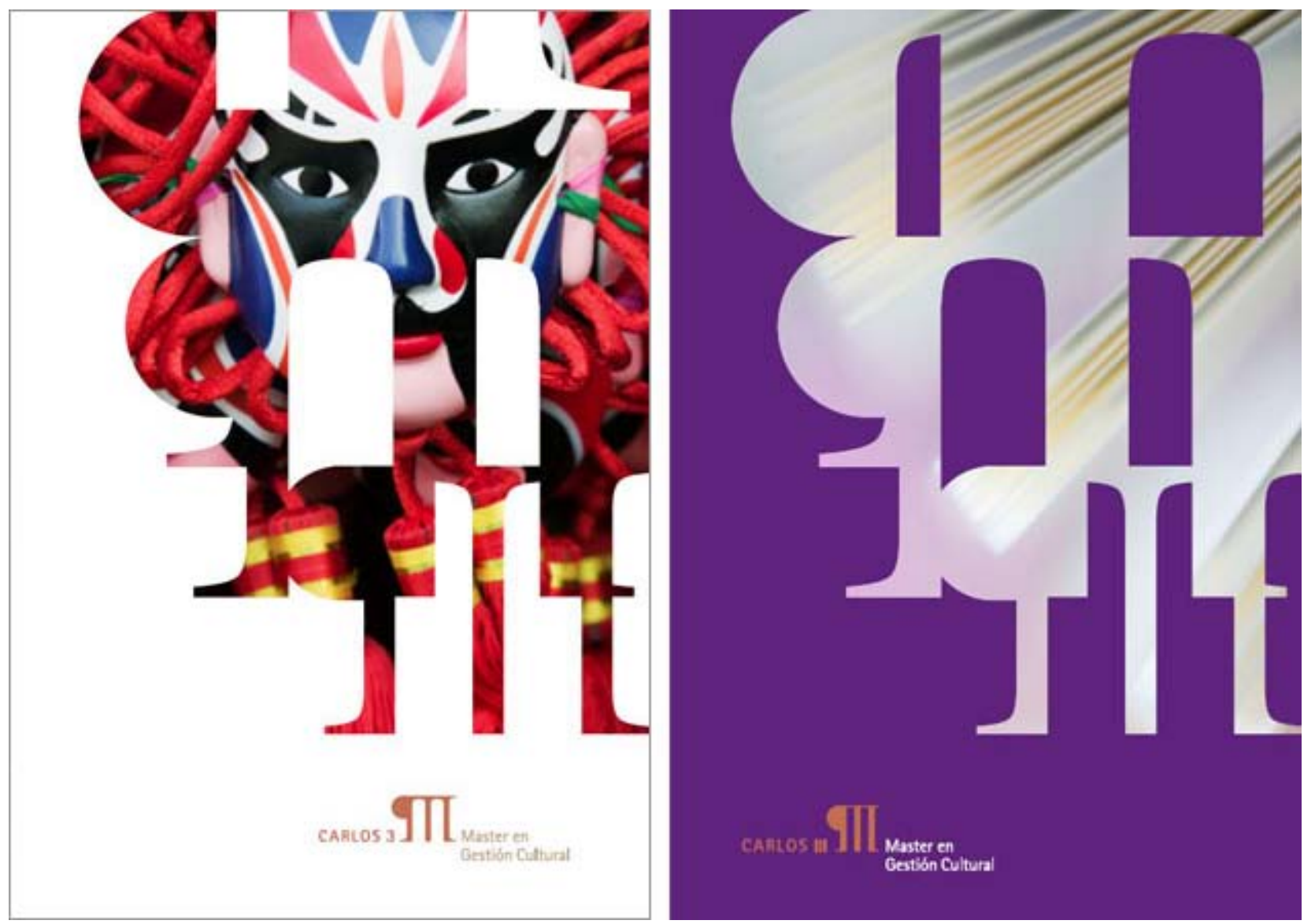

Fig. 10. Ejemplos de cartelería basados en la imagen corporativa del Máster en Gestión Cultural.

El simple ejercicio de superposiciones del símbolo y el juego de tamaños sirvió para reforzar esa idea pretendida de tercera dimensión o sugerencia de profundidades y capas. En las aplicaciones y usos del símbolo se utilizaron diversos "rellenos" — de color, tipográficos o fotográficos— buscando transmitir en los diversos soportes de comunicación la propia diversidad de temas del máster sin menoscabo de la identidad gráfica buscada como objetivo principal del proyecto. 


\section{Tercer tiempo: la Feria es un collage}

La Feria del Libro de Madrid llega a su edición 75. Gran parte de la experiencia humana funciona a base de capas o niveles. La Feria tiene 75 capas. Año tras año se han ido superponiendo, de forma secuenciada y, en parte, aleatoriamente capas, estratos, niveles relacionados todos ellos con lo que conocemos, como la cultura.

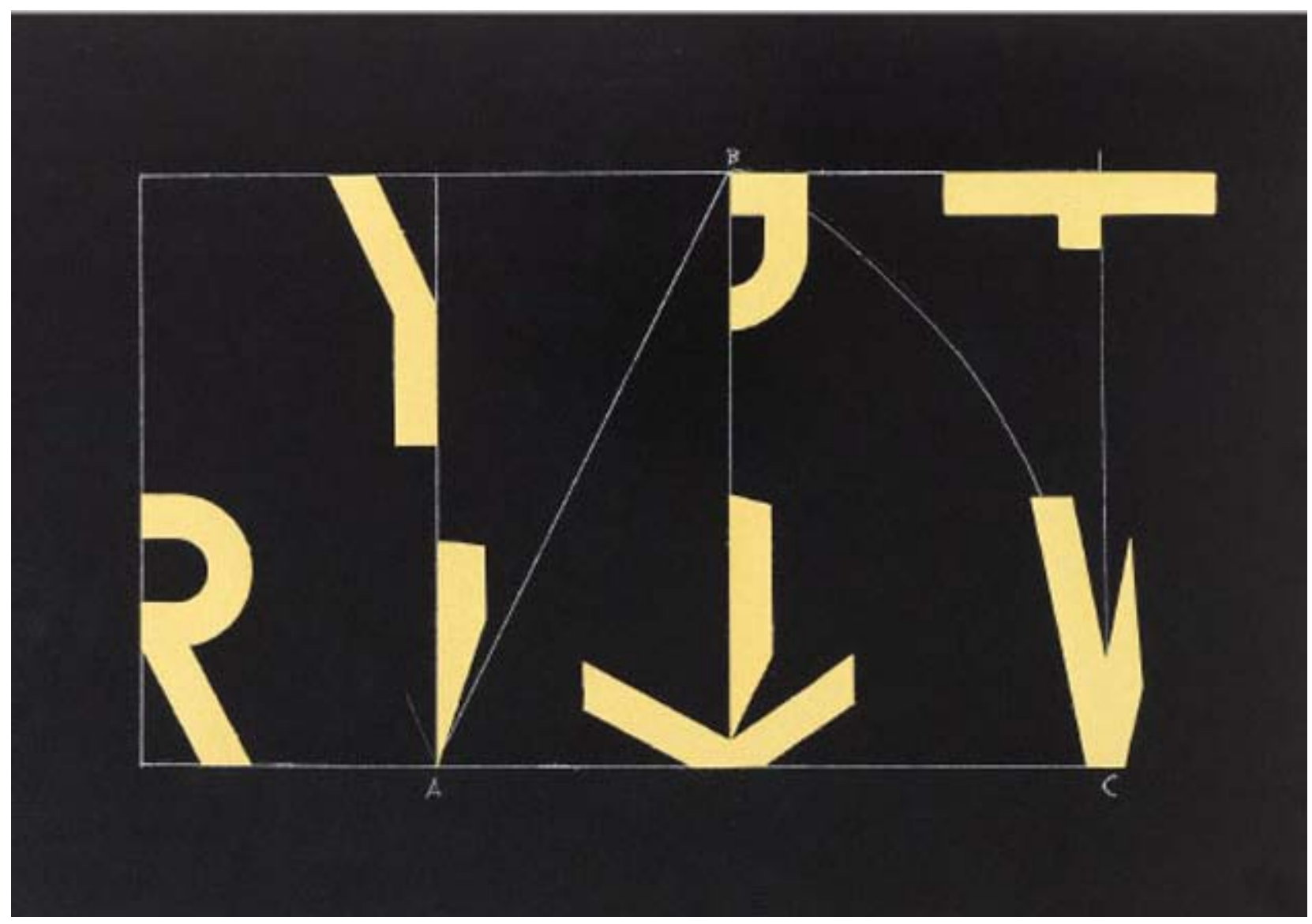

Fig. 11. Collage realizado por Emilio Gil.

Según afirma el artista británico David Hockney, "entendemos el presente comparándolo con el pasado añadiendo una capa sobre otra". Creo que la metáfora visual más próxima a esa forma de crecimiento es una imagen construida con la técnica del collage, añadiendo, encajando "piezas" con un origen anterior y que, al igual que el trabajo de creación en la escritura, nacen unas de otras ajustándose a lo que ya existía anteriormente.

En el cartel de la 75 edición de la Feria del Libro de Madrid se ha buscado ensamblar piezas que remiten al inicio de la lectura y la escritura por parte del niño, futuro lector, las técnicas de impresión, el trabajo de los diseñadores que conforman ese artefacto al que llamamos libro y el futuro de éste.

Lo físico, lo táctil, aquello que experimentamos también desde varios niveles y sentidos está aquí integrado, encajado y orgulloso de su materialidad. ¡Larga vida al libro! 

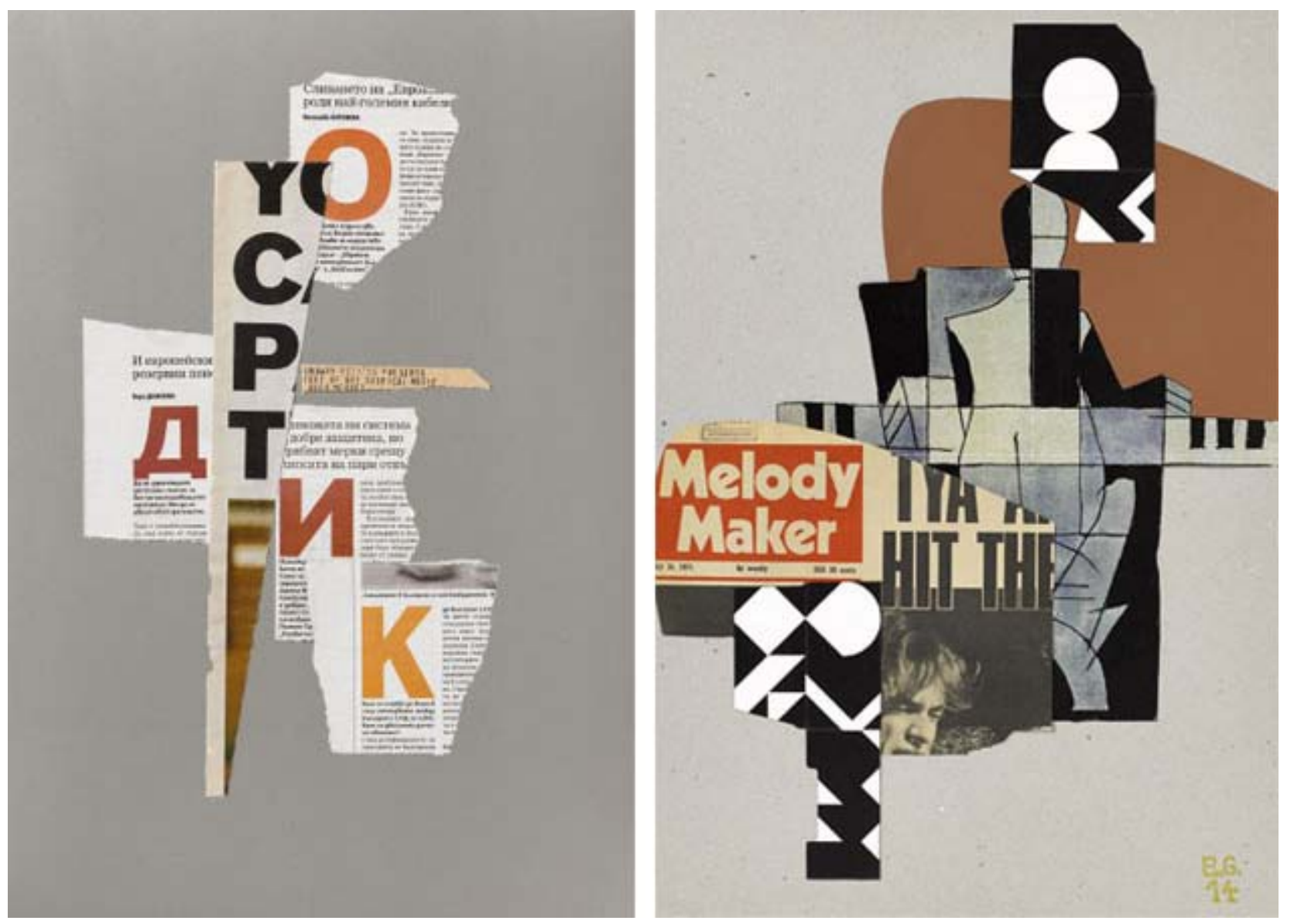

Fig. 12. Collages realizados por Emilio Gil.
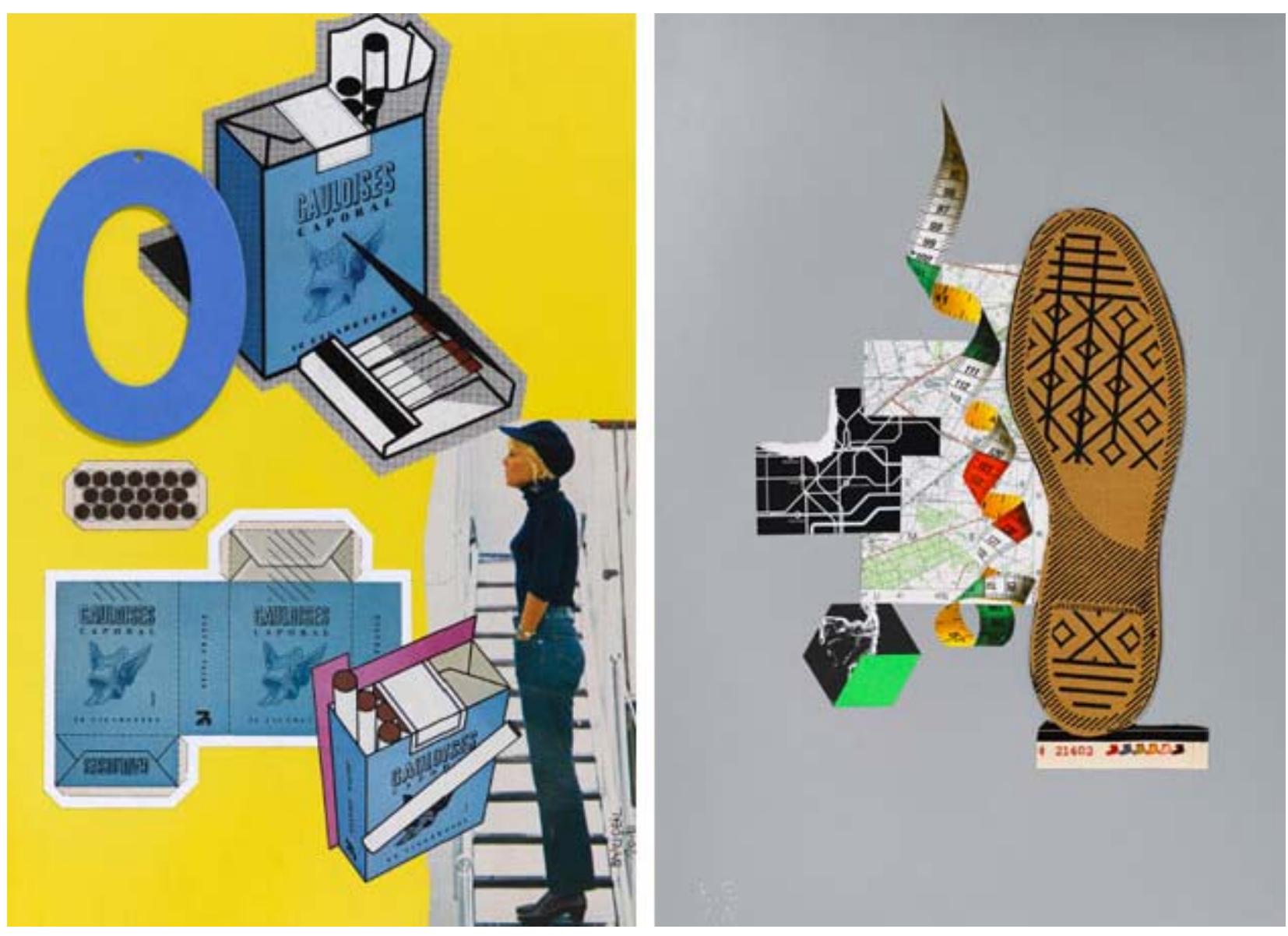

Fig. 13. Collages realizados por Emilio Gil. 

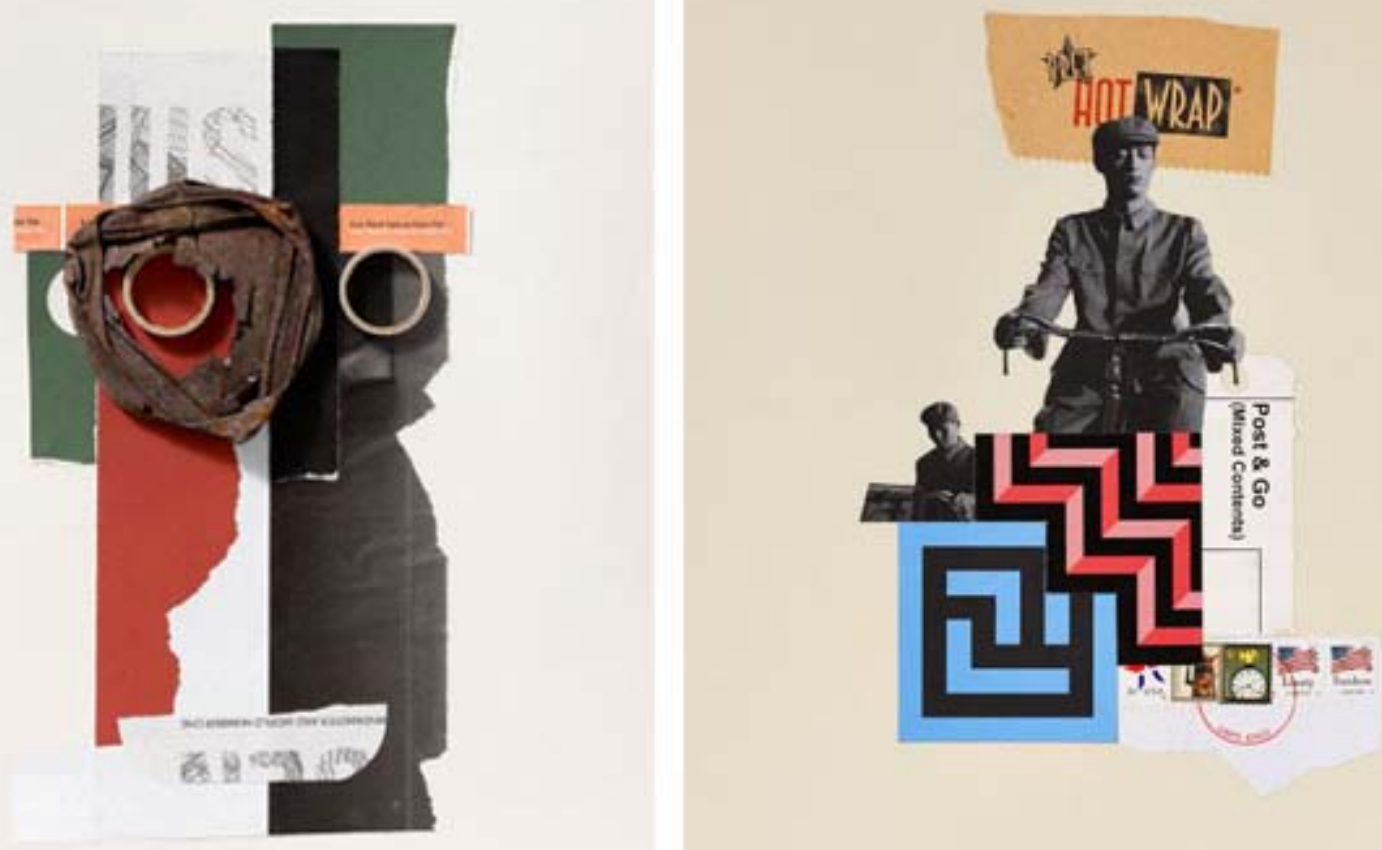

Fig. 14. Collages realizados por Emilio Gil.
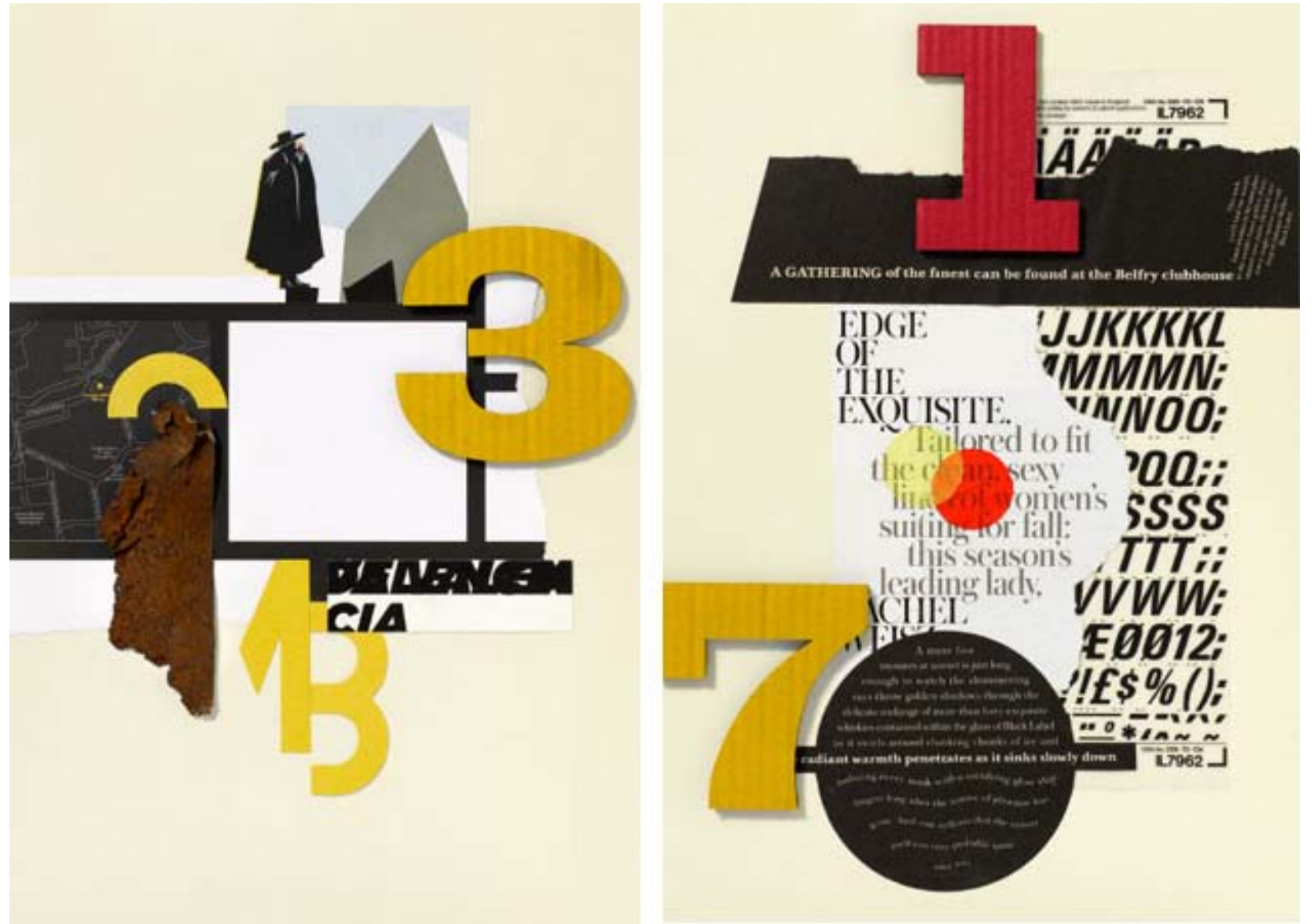

Fig. 15. Collages realizados por Emilio Gil. 
*Emilio Gil, medalla de Oro al Mérito en las Bellas Artes, es diseñador gráfico y teórico del diseño. Formado en la SVA (School of Visual Arts) de Nueva York y en la Central St. Martins de Londres en Comisariado de exposiciones, en 1980 funda Tau Diseño, una de las empresas españolas pioneras en servicios de diseño.

Premio Laus de Oro 1995 en Diseño Editorial, premio Donside en Gran Bretaña y Certificate of Excellence del Type Directors Club de Nueva York, es autor del libro Pioneros del Diseño Gráfico en España (Index Book, 2007) y coautor de Lo bello de las cosas (Gustavo Gili. 2007). Además, ha comisariado las exposiciones Signos del siglo. 100 años de Diseño Gráfico en España, en el Museo Reina Sofía; ¿Dissenyes o Diseñas? (Madrid, Berlín, Sofia); $24 \times 365$. Diseño Gráfico para la Comunicación pública (CBA, Madrid, 2008), y Grafistas. Diseño gráfico en España 19391975 (Museo Nacional de Artes Decorativas, Madrid, 2011).

Revista internacional de investigación, innovación y desarrollo en Diseño • ISSN 1889-433 x

Grupo de investigación Lenguaje Visual y Diseño Aplicado • Plan Andaluz de Investigación • E. Politécnica S. • Universidad de Málaga 